\title{
Compartimentação paisagística multiescalar da bacia hidrográfica do rio Uberabinha (Minas Gerais, Brasil) por meio da perspectiva geossistêmica
}

\author{
Multiscale landscape compartmentation of the Uberabinha river basin (Minas \\ Gerais, Brazil) through the geosystemic perspective
}

\author{
Rafael Mendes Rosa ${ }^{1}$ \\ Vanderlei de Oliveira Ferreira ${ }^{2}$
}

\begin{abstract}
Palavras-chave:
Geossistema

Planejamento ambiental

Unidades de paisagem

Resumo

O uso inadequado dos recursos naturais em contextos espacialmente diferenciados sob vários aspectos nas bacias hidrográficas conduz à degradação ambiental e aos problemas sociais. Nesse sentido, as ações de gestão são fundamentais e devem partir do princípio de que as unidades hidrográficas são internamente heterogêneas, complexas e multifacetadas, configurando-se como um conjunto de situações variadas. Este artigo relata resultados de pesquisa dedicada à aplicação de um procedimento metodológico de compartimentação paisagística multiescalar baseado na adaptação das contribuições de dois autores clássicos: Georges Bertrand e Jean Tricart. A bacia do rio Uberabinha, localizada no estado de Minas Gerais, adotada como área de estudo, foi caracterizada do ponto de vista fisiográfico e subdividida ordenadamente em dois geossistemas, quatro geocomplexos e oito geofácies. Unidades menores, denominadas geótopos, também foram identificadas enquanto exemplos. A partir dos mapas de componentes fisiográficos e de cobertura e uso da terra distribuídos em intervalos temporais situados entre 1985 e 2020 foi possível categorizar a vulnerabilidade dos terrenos quanto à perda de solos. Por fim, perfis geoecológicos foram elaborados para organização de uma síntese da realidade terrestre da bacia numa perspectiva vertical (geohorizontes). Diante do exposto, o trabalho contribuiu como uma análise da bacia do rio Uberabinha baseada na perspectiva geossistêmica, visto que sua exploração tem se mostrado ecologicamente predatória, assim como na maioria das bacias hidrográficas brasileiras.
\end{abstract}

Keywords:

Geosystem

Environmental planning

Landscape units

\begin{abstract}
The inappropriate use of natural resources in spatially differentiated contexts under various aspects in watersheds leads to environmental degradation and social problems. In this sense, management actions are fundamental and should start from the principle that hydrographic units are internally heterogeneous, complex and multifaceted, configuring themselves as a set of varied situations. This article reports the results of research dedicated to the application of a methodological procedure to multiscale landscape compartmentalization based on the adaptation of the contributions of two classic authors: Georges Bertrand and Jean Tricart. The Uberabinha river basin, located in the state of Minas Gerais (Brazil), adopted as the study area, was characterized from a physiographic point of view and neatly subdivided into two geosystems, four geocomplexes and eight geofacies. Smaller units, called geotopes, were also identified as examples. From the maps of physiographic components and land cover and use distributed in time intervals between 1985 and 2020, it was possible to categorize the vulnerability of the land to soil loss. Finally, geoecological profiles were elaborated to organize a synthesis of the terrestrial reality of the basin in a vertical perspective (geohorizons). Given the above, the work contributed as an analysis of the Uberabinha river basin based on a geosystemic perspective, since its exploitation has shown to be ecologically predatory, as well as in most Brazilian hydrographic basins.
\end{abstract}




\section{INTRODUÇÃO}

A utilização inadequada dos recursos naturais em contextos espacialmente diferenciados nas bacias hidrográficas conduz à degradação ambiental e aos problemas sociais. Nesse sentido, a compartimentação da paisagem é útil para proposição de melhorias da qualidade ambiental, pois as bacias são heterogêneas, complexas e multifacetadas. As particularidades internas devem ser consideradas nas propostas de gerenciamento, sobretudo porque as bacias hidrográficas são unidades territoriais universalmente aceitas para o planejamento e a gestão ambiental (SANTOS, 2004).

Para Rodriguez, Silva e Cavalcanti (2007), a paisagem é um objeto de investigação geoecológica, servindo de base para o planejamento do território, pois, a partir do potencial dos recursos naturais, é possível formular estratégias de uso de suas unidades paisagísticas. Os autores ressaltam que a paisagem deve ser concebida como um sistema integrado, visto que os componentes isolados não possuem propriedades integradoras.

Diversos artigos recorrentemente publicados sobre compartimentação da paisagem e avaliação da vulnerabilidade à perda de solos baseiam-se na abordagem geossistêmica (influenciada pela Teoria Geral dos Sistemas) para entendimento da estrutura e processos naturais atuantes. Os trabalhos de análise ambiental integrada começaram a ganhar força a partir da segunda metade do século XX, com destaque a autores da escola soviética, como Sotchava (1977), e da escola francesa, por exemplo, Bertrand (1971) e Tricart (1977).

Desde então, diversos autores, no Brasil e no mundo, têm se apoiado nessas concepções para elaboração de compartimentações paisagísticas de bacias hidrográficas e outras unidades territoriais, embora a maioria delas seja executada a partir de adaptações das metodologias dos referidos autores clássicos. Pode-se citar Oliveira e Marques Neto (2015), Marent e Portilho (2017), Arias-García, GómezZotano e Delgado-Peña (2017), Nicolau (2018), Lima e Corrêa (2019) e Oliveira, Viadana e Pereira (2019).

A abordagem de Cavalcanti $(2013,2014)$ é inteiramente baseada em pesquisadores da escola soviética, cuja proposta é a busca de uma síntese naturalista com a diferenciação cartográfica das paisagens. Outra perspectiva de destaque é a Geoecologia das Paisagens de Rodriguez, Silva e Cavalcanti (2007), que têm orientado autores no Brasil, como Trombeta e
Leal (2016), Miranda et al. (2018) e Faria e Silva (2020).

Em outras publicações que não mencionam diretamente os autores clássicos, as concepções geossistêmicas de alguma forma são aplicadas, visto que há integração de componentes paisagísticos para identificação de homogeneidades do território, como nas publicações de Gülçin e Yilmaz (2020) e Carlier et al. (2021). A compartimentação de Carlier et al. (2021), por exemplo, baseia-se na Convenção Europeia da Paisagem, tratado do ano 2000, sendo realizada iterações de agrupamento das unidades fisiográficas e cobertura da terra para classificação estatística das paisagens irlandesas.

Embora haja uma variedade de metodologias de compartimentação das paisagens observa-se que os estudos que envolvem $o$ viés geossistêmico não têm apresentado inovações metodológicas significativas, sendo em muitos casos replicações e adaptações de modelos baseados nos clássicos. No entanto, do ponto de vista procedimental melhorias têm, de fato, ocorrido devido ao avanço das geotecnologias disponíveis para coleta, processamento e análise de informações geográficas. Os softwares de geoprocessamento e o WebGIS são cada vez mais úteis na geração de produtos cartográficos precisos.

Com base no exposto, o presente artigo apresenta um estudo de caso dedicado a identificar e caracterizar cenários paisagísticos da bacia hidrográfica do rio Uberabinha, situada no estado de Minas Gerais. O objetivo é identificar, por meio de múltiplas escalas, unidades paisagísticas internas, partindo da consideração da bacia em sua totalidade e dirigindo-se às particularidades locais. Por meio deste diagnóstico é possível encontrar as vulnerabilidades naturais de cada uma das unidades delimitadas.

Nesse contexto, com a utilização de técnicas de geoprocessamento o presente artigo visa identificar especificidades internas da área de estudo a partir de pressupostos de autores clássicos da escola francesa: Bertrand e Bertrand (2009) e Tricart (1977). A proposta contempla a identificação das geofácies de Bertrand e Bertrand (2009) por meio de mapa temático e perfis geoecológicos que possuem respaldo nos geohorizontes definidos pelos autores. As geofácies foram selecionadas como componentes geomorfológicos para o levantamento da vulnerabilidade à perda de solos, de Crepani et al. (2001), cuja base é Tricart (1977).

$\mathrm{Na}$ busca por uma abordagem integrada que atenda aos estudos de bacias hidrográficas, as 
concepções sobre a teoria dos geossistemas de autores da escola francesa podem contribuir para a melhoria da identificação das heterogeneidades internas. Suas metodologias podem ser concebidas para o desenvolvimento de procedimentos metodológicos atualizados. Os resultados podem fornecer subsídios para a tomada de decisão no âmbito do planejamento ambiental de bacias hidrográficas.

\section{ÁREA DE ESTUDO}

A área definida para estudo é a bacia hidrográfica do rio Uberabinha, cujo rio principal é afluente da margem esquerda do rio Araguari (estadual), que por sua vez deságua no Paranaíba (federal). Essa bacia, cuja área total é de 2.189,42 km² está situada nas Regiões Intermediárias de Uberlândia e Uberaba (IBGE, 2017), abrangendo parte de três municípios: 20\% em Uberaba, 70\% em Uberlândia e 10\% em Tupaciguara (ROSA, 2017) (Figura 1). Trata-se de um importante manancial que serve ao abastecimento público da cidade de Uberlândia, cuja população estimada é de 706.597 habitantes (IBGE, 2021). 


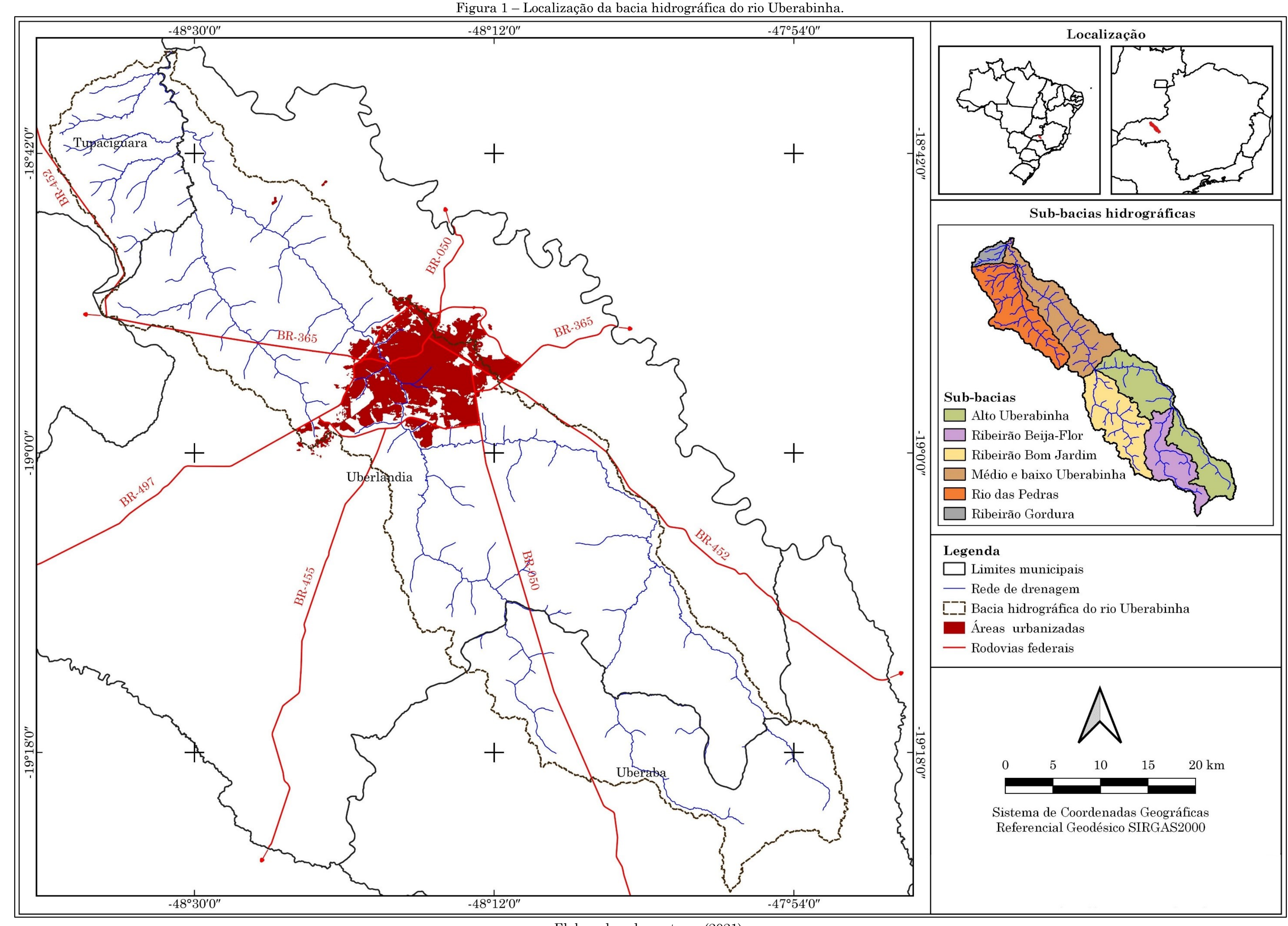

Elaborado pelos autores (2021) 


\section{PROCEDIMENTO METODOLÓGICO}

A metodologia contemplou, inicialmente, o levantamento dos aspectos naturais, da cobertura e uso da terra e a obtenção da vulnerabilidade à perda de solos. $\mathrm{O}$ trabalho foi desenvolvido por meio de referências bibliográficas, confecção de mapas temáticos e elaboração de perfis geoecológicos.

Os arquivos vetoriais do território brasileiro e da rede drenagem são do IBGE (2020) e do IGAM (2012), respectivamente. O modelo digital de elevação utilizado para delimitação da bacia hidrográfica do rio Uberabinha é o Alos Palsar (2021). As ferramentas para sua obtenção são "Fill sinks (Wang \& Liu)", "Channel network and drainage basins" e "Upslope area", todos do software SAGA, integrado ao QGIS 3.18.3 with GRASS 7.8.5.

Os mapas temáticos também foram confeccionados no QGIS 3.18.3 with GRASS 7.8.5 a partir de arquivos vetoriais e raster obtidos gratuitamente em endereços eletrônicos especializados. As fontes do tema geologia são Pacheco et al. (2017) e Rosa, Ferreira e Brito (2019). A hipsometria e a declividade foram geradas por meio de imagem Alos Palsar (2021). Os intervalos de elevação foram estabelecidos nas propriedades da imagem, enquanto a declividade foi obtida pela opção "Declive", sendo fatiadas as classes nas propriedades do raster.

Ainda em relação aos temas, o mapa de solos foi elaborado por meio da vetorização da imagem de solos da EPAMIG (1980). A pluviosidade foi obtida a partir de dados interpolados de estações pluviométricas situadas na área de estudo e entorno. Esses dados são disponibilizados pelo portal HidroWeb (ANA, 2021). A ordem dos canais corresponde à uma informação da tabela de atributos do arquivo vetorial do IGAM (2012). O mapa de cobertura uso da terra foi obtido com a imagem do Projeto MapBiomas Coleção 6 (2021).

Entretanto, outros mapas foram elaborados a partir de metodologias específicas, como a compartimentação dos geossistemas e a vulnerabilidade à perda de solos, baseados em autores da escola francesa dos estudos geossistêmicos: Bertrand e Bertrand (2009) e Tricart (1977). Os geossistemas correspondem aos compartimentos geomorfológicos, enquanto os geocomplexos foram organizados por aspectos morfométricos. Para a delimitação das geofácies foram definidos intervalos de elevação a partir da ferramenta "r.reclass" do QGIS 3.18.3 with
GRASS 7.8.5. Para a vulnerabilidade à perda de solos foi utilizada a "calculadora raster" do referido software.

A perspectiva metodológica utilizada para a compartimentação dos geossistemas é parte do sistema GTP (Geossistema-TerritórioPaisagem), de Bertrand e Bertrand (2009). Nessa metodologia multiescalar o geossistema é a entrada naturalista, associado ao tempo geológico, e pode ser identificado como uma grande área relativamente homogênea do ponto de vista fisiográfico. Cada geossistema pode ser compartimentado em geofácies a partir da observação de porções ainda mais homogêneas e outras unidades menores nas geofácies também podem ser representadas, os geótopos.

Bertrand e Bertrand (2009) ainda consideram importante nas análises paisagísticas a perspectiva vertical (geohorizontes), que podem ser retratadas por meio de perfis geoecológicos. Assim, foram traçados quatro perfis que contemplam uma síntese da realidade terrestre de cada geocomplexo. Santos, Ruchkys e Travassos (2021) ressaltam que os perfis favorecem as leituras horizontais e verticais e a interpretação de correlações entre os componentes paisagísticos. Para Cavalcanti (2014, p. 37), os perfis podem ser denominados de seções-tipo e constituem em modelo cujo intuito é "caracterizar as variações paisagísticas ao longo de gradiente de relevo".

Os perfis geoecológicos foram desenvolvidos no QGIS 3.18.3 with GRASS 7.8.5. Inicialmente foram traçados os transectos com arquivos vetoriais do tipo linha e gerados os perfis por meio do plugin "Profile tool". Em seguida, foram adicionados no compositor de impressão todas as faixas correspondentes à cobertura e uso da terra, solos, geofácies, geologia e vulnerabilidade à perda de solos.

Em relação a Tricart, seus pressupostos metodológicos conhecidos como "ecodinâmica" (TRICART, 1977) serviram de base para Crepani et al. (2001) estabelecer graus de vulnerabilidade à perda de solos (Tabela 1). Para Tricart (1977), as áreas onde se predominam a pedogênese seriam os meios estáveis, as porções de maior instabilidade (morfogênese) corresponderiam aos meios fortemente instáveis e, por fim, os terrenos em que há um equilíbrio entre pedogênese e morfogênese são denominados meios intergrades. 
Tabela 1 - Escala de vulnerabilidade à perda de solos.

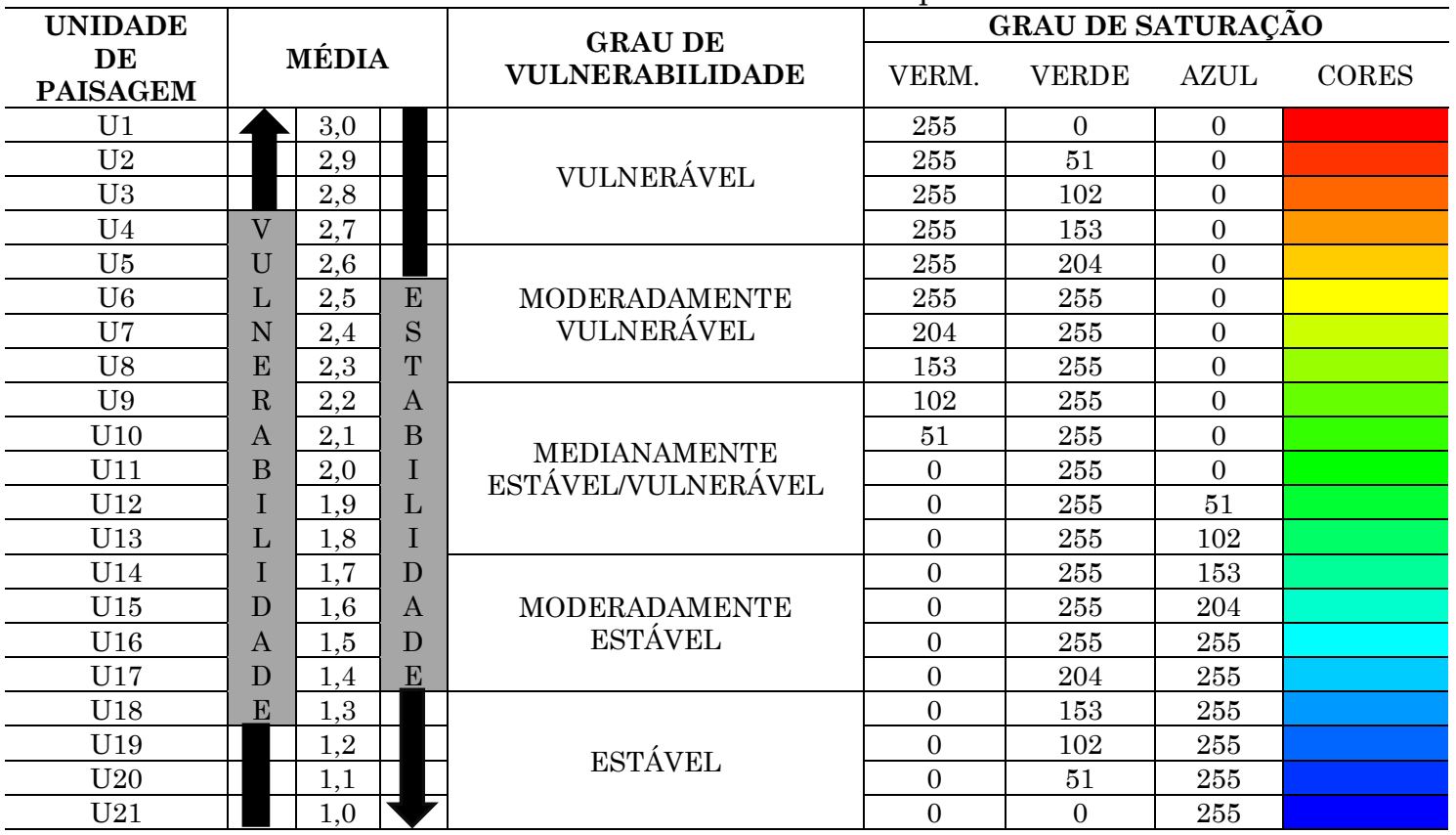

Fonte: Crepani et al. (2001, p. 22).

Com base na escala de Crepani et al. (2001), as variáveis fisiográficas apresentam diferentes valores de vulnerabilidade. Dessa forma, o trabalho contemplou a indicação dos valores na tabela de atributos de cada variável dos componentes geologia, geofácies, solos, pluviosidade e cobertura e uso da terra. Posteriormente os arquivos vetoriais foram convertidos em raster e sobrepostos na "Calculadora Raster" do QGIS 3.18 .3 with GRASS 7.8.5 para extração da média aritmética. $\mathrm{O}$ resultado indica o grau de vulnerabilidade a partir da seguinte equação:

$$
V=\frac{(G e o l+G e o f+S o l+I P+C U T)}{5}
$$

Onde:

$V=$ Vulnerabilidade
Geol $=$ Vulnerabilidade para o tema Geologia Geof $=$ Vulnerabilidade para o tema Geofácies $\mathrm{Sol}=$ Vulnerabilidade para o tema Solos $I P=$ Vulnerabilidade para o tema Intensidade Pluviométrica

$C U T=$ Vulnerabilidade para o tema Cobertura e Uso da Terra.

Após o levantamento dos aspectos naturais, da cobertura e uso da terra e da vulnerabilidade à perda de solos foram elaborados perfis geoecológicos representando os geocomplexos identificados (Quadro 1). Trata-se de uma caracterização esquemática capaz de representar as variações dos componentes fisiográficos ao longo de uma seção topográfica (CAVALCANTI, 2014), baseados nos geohorizontes de Bertrand e Bertrand (2009).

Quadro 1-Aspectos esquemáticos do procedimento metodológico.

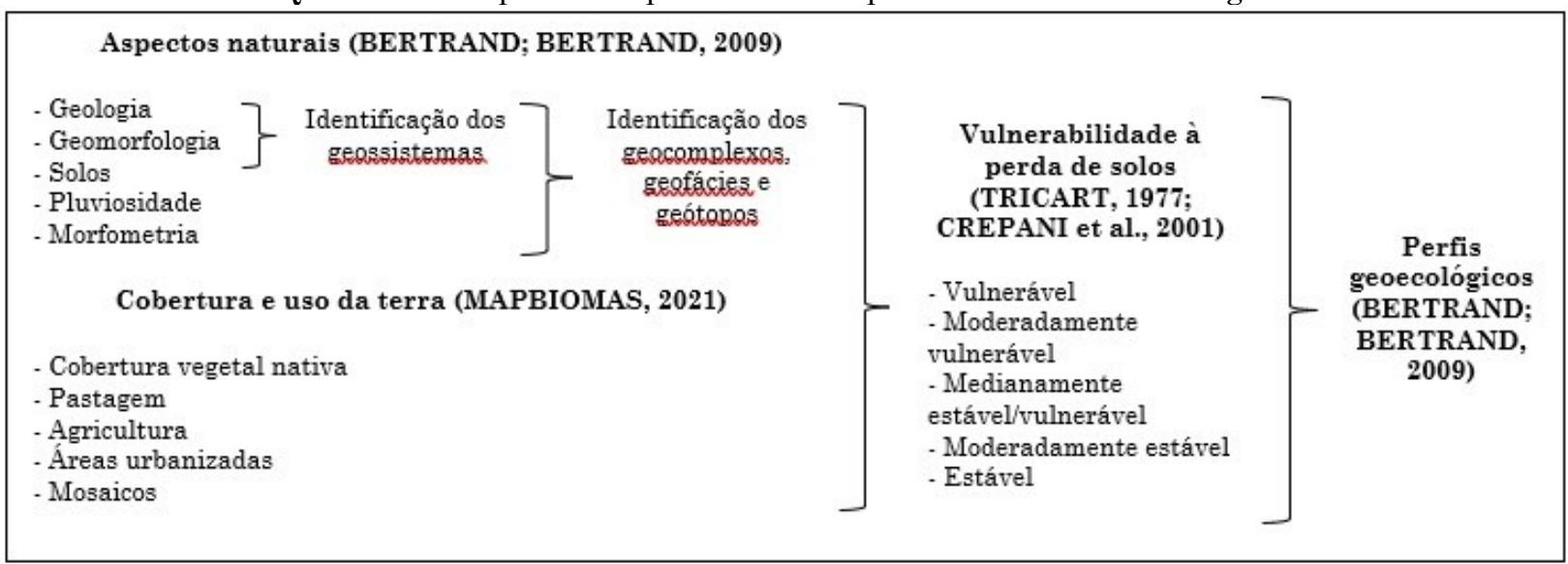

Elaborado pelos autores (2021). 


\section{RESULTADOS}

\section{Aspectos naturais}

A Bacia Sedimentar do Paraná é o contexto geotectônico predominante na bacia do rio Uberabinha, cujas rochas presentes na área de estudo formaram-se no Período Cretáceo (Mesozoico). Entretanto, no trecho final do rio principal afloram rochas do Orógeno Brasília (Neoproterozoico). Essas rochas de embasamento regional correspondem aos micaxistos do Grupo Araxá (SEER; MORAES, 2017).

As rochas do Cretáceo inferior são os basaltos da Formação Serra Geral (Grupo São Bento) e do Cretáceo superior são os arenitos da Formação Marília (Grupo Bauru). Ressalta-se que ocasionalmente são encontrados arenitos da Formação Botucatu (não mapeáveis) sob os micaxistos ou em forma de lentes intertrápicas com os basaltos (PACHECO et al., 2017).

No Cenozoico ocorreram processos de peneplanização, dissecação do relevo e formação de coberturas lateríticas. No Paleógeno, o aplainamento originou a "Superfície SulAmericana" sob condições de aridez. No Neógeno, sob clima úmido, essa Superfície experimentou o processo "Ciclo Velhas", formando os planaltos. Por fim, no Quaternário o "Ciclo Paraguaçu" exumou as rochas do Neproterozoico, (KING, 1956; MOREIRA; PEREZ FILHO, 2020).
Diante do exposto observa-se que a bacia do rio Uberabinha apresenta dois grandes compartimentos geomorfológicos. O primeiro, situado nas bacias de alto curso e do Bom Jardim, é uma chapada. As porções mais elevadas (os pediplanos) são os resquícios da "Superfície Sul-Americana". O restante da bacia corresponde a um planalto dissecado, associado ao "Ciclo Velhas e, em menor abrangência, ao "Ciclo Paraguaçu", com exposição do Grupo Araxá.

De modo a salientar a presença dos compartimentos mencionados e observando-se os mapas de hipsometria e declividade da Figura 2 , nota-se que a elevação da chapada, em grande parte, está acima de $900 \mathrm{~m}$. As classes de declividade na chapada são: $0 \%$ a $3 \%$ (plano), $3 \%$ a $8 \%$ (suave ondulado) e $8 \%$ a $20 \%$ (ondulado). No planalto encontram-se as classes $20 \%$ a $45 \%$ (forte ondulado) e maior que $45 \%$ (montanhoso) nos vales mais dissecados.

A respeito das classes de solos da área de estudo (Quadro 2 e Figura 2), os Latossolos são predominantes, sendo encontrados na chapada e no planalto. Contudo, algumas classes de solos são encontradas somente em um dos compartimentos geomorfológicos. Os Latossolos Vermelho-Amarelos estão presentes na chapada, enquanto que Cambissolos e Neossolos restringem-se ao planalto, sobretudo nas vertentes de maior declividade (EPAMIG, 1980; SANTOS et al., 2018).

Quadro 2 - Classes de solos da bacia hidrográfica do rio Uberabinha.

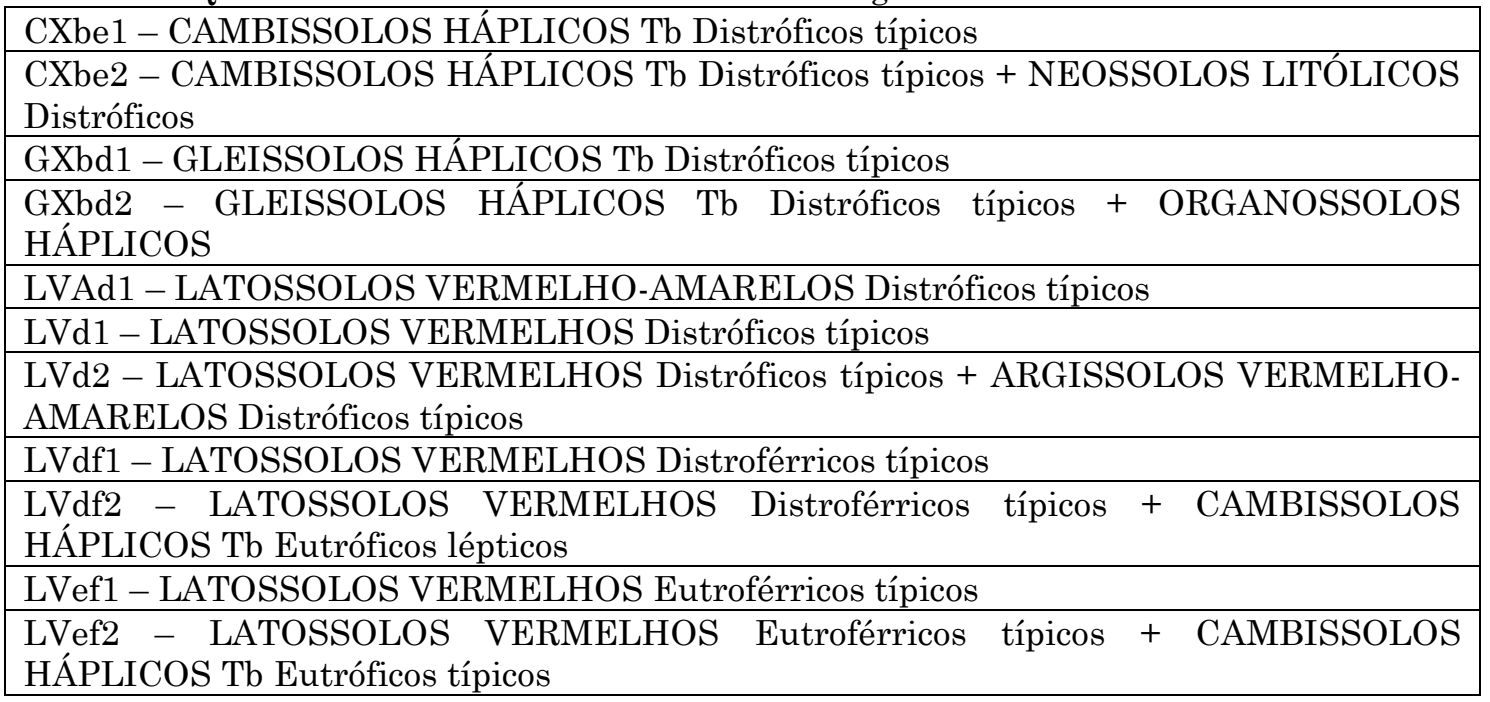

Fonte: Adaptado de EPAMIG (1980) e Santos et al. (2018).

A fase vegetacional associada aos solos compreende as três formações fitofisionômicas encontradas no "Domínio dos Cerrados" (AB'SABER, 2012): florestal, savânica e campestre. A formação florestal abrange as fases floresta tropical caducifólia, subcaducifólia, hidrófila de várzea, bem como o cerradão tropical subcaducifólio. A fase cerrado 
tropical subcaducifólio insere-se na formação savânica e o campo hidrófilo de várzea na formação campestre.

Em relação às condições climáticas a bacia do rio Uberabinha situa-se na zona Tropical Brasil Central (IBGE, 2002). As temperaturas médias superam $18^{\circ} \mathrm{C}$ na maior parte do ano e o período de seca varia de 4 a 5 meses. A média de pluviosidade anual abrange o intervalo de 1.400 $\mathrm{mm}$ a $1.600 \mathrm{~mm}$, sendo duas estações bem definidas: verão chuvoso e quente e inverno seco.

Outro componente importante para identificação dos compartimentos geomorfológicos é a morfometria. Feltran Filho e Lima (2007) identificaram que as porções com menor densidade de rios estão em terrenos sedimentares, de topografia plana a suave ondulada. Nas áreas mais onduladas e de canais mais encaixados, de substrato basáltico, aumenta-se a quantidade de canais.

Sobre a hierarquia dos canais de Strahler (1952) o trecho final do rio Uberabinha é de ordem 6. Os trechos finais do rio alto Uberabinha, ribeirões Beija-Flor e Bom Jardim e rio das Pedras são de ordem 4. Além da hierarquia dos canais, os mapas dos componentes descritos da bacia do rio Uberabinha contribuem para a análise dos aspectos fisiográficos (Figura 2). 
Figura 2 - Componentes fisiográficos da bacia hidrográfica do rio Uberabinha. A) Geologia; B) Hipsometria; C) Declividade; D) Solos; E) Pluviosidade; F) Ordem dos canais.
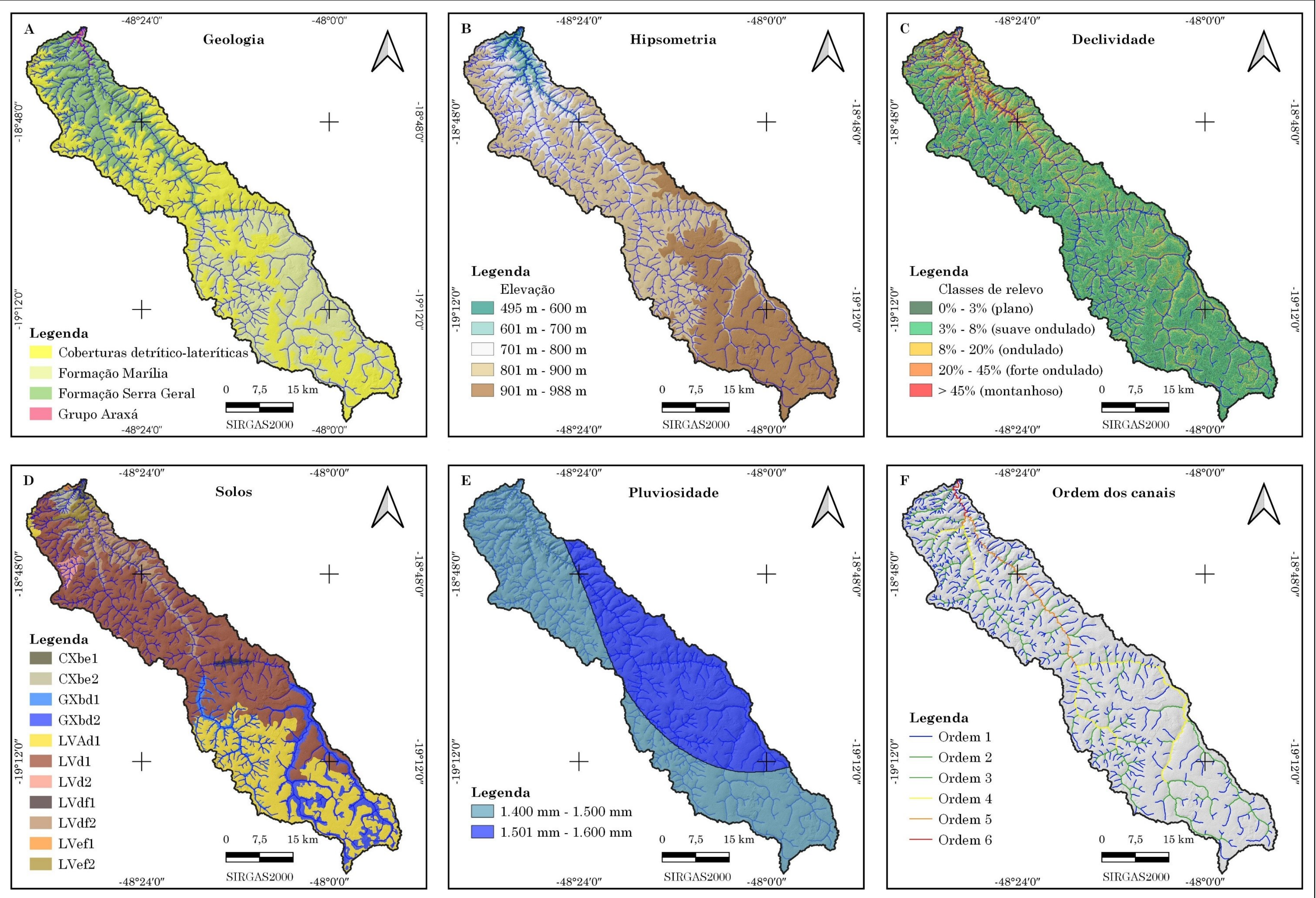

Elaborado pelos autores (2021). 
Com base em Bertrand e Bertrand (2009), os dois compartimentos geomorfológicos identificados (chapada e planalto) podem ser considerados como sendo dois geossistemas: a Chapada Uberlândia-Uberaba e o Planalto Dissecado do Triângulo Mineiro.

O geossistema Chapada Uberlândia-Uberaba pode ainda ser dividido em dois geocomplexos: as Superfícies Aplainadas Muito Pouco Dissecadas e as Superfícies Aplainadas Pouco Dissecadas. Essa compartimentação deve-se ao fato de haver um menor poder de geração de canais de primeira ordem nas sub-bacias alto Uberabinha e ribeirão Beija-Flor (muito pouco dissecado) quando comparado ao ribeirão BeijaFlor (pouco dissecado).

No Planalto Dissecado do Triângulo Mineiro, outros dois geocomplexos são perceptíveis quando se analisa os componentes fisiográficos: Patamares Pouco Rebaixados e Patamares Rebaixados e Vale Encaixado. A diferença ocorre devido a uma mudança muito perceptível na elevação e na declividade, sendo que no último geocomplexo são encontradas as rochas do Grupo Araxá.

Cada geocomplexo é ainda dividido em geofácies, que podem se repetir entre eles, mesmo que sejam diferentes em algum grau. São considerados como geofácies o pediplano degradado etchplanado, o modelado de dissecação homogênea, as planícies e terraços fluviais e os entalhamentos de incisões variadas e a dissecação estrutural. Em cada geofácie contempla-se também exemplos das menores unidades homogêneas consideradas por Bertrand e Bertrand (2009), os geótopos (Figura $3)$.

\section{Cobertura e uso da terra}

Na década de 1960, a bacia do rio Uberabinha apresentava significativa cobertura vegetal nativa. Contudo, devido aos incentivos governamentais as primeiras alterações dos espaços naturais ocorreram na década de 1970 com a ascensão da silvicultura e agricultura (SCHNEIDER, 1996). Nesse contexto, o crescimento cidade de Uberlândia, situada no médio curso, intensificou-se pela ampliação de indústrias e a consolidação da infraestrutura de transporte.

Conforme cálculo de áreas realizado a partir das imagens do Projeto MapBiomas (2021) desde a década de 1980 as classes de cobertura e uso da terra são as mesmas, porém áreas de ocupação diferenciadas ao longo do período 1985-2020 (Tabela 2). Os dados corroboram com indicação de que as áreas naturais têm sido convertidas em ocupações antrópicas, o que indica uma apropriação contínua dos recursos naturais da bacia do rio Uberabinha.

A área de estudo perdeu $11,34 \%$ de cobertura vegetal nativa (formações florestal, savânica e campestre) entre 1985 e 2020. Em 1985, a vegetação ocupava $26,93 \%$, enquanto que em 2020 passou a estar presente em apenas $15,59 \%$ da bacia. Ao longo desses 35 anos a soja que representava irrisórios $0,45 \%$ de ocupação em 1985 se tornou a maior classe de uso da terra em $2020,24,97 \%$. A pastagem diminuiu consideravelmente, mas ainda é uma forma de ocupação relevante, sendo 39,61\% em 1985 e $17,64 \%$ em 2020. A área urbanizada mais que duplicou a ocupação. 


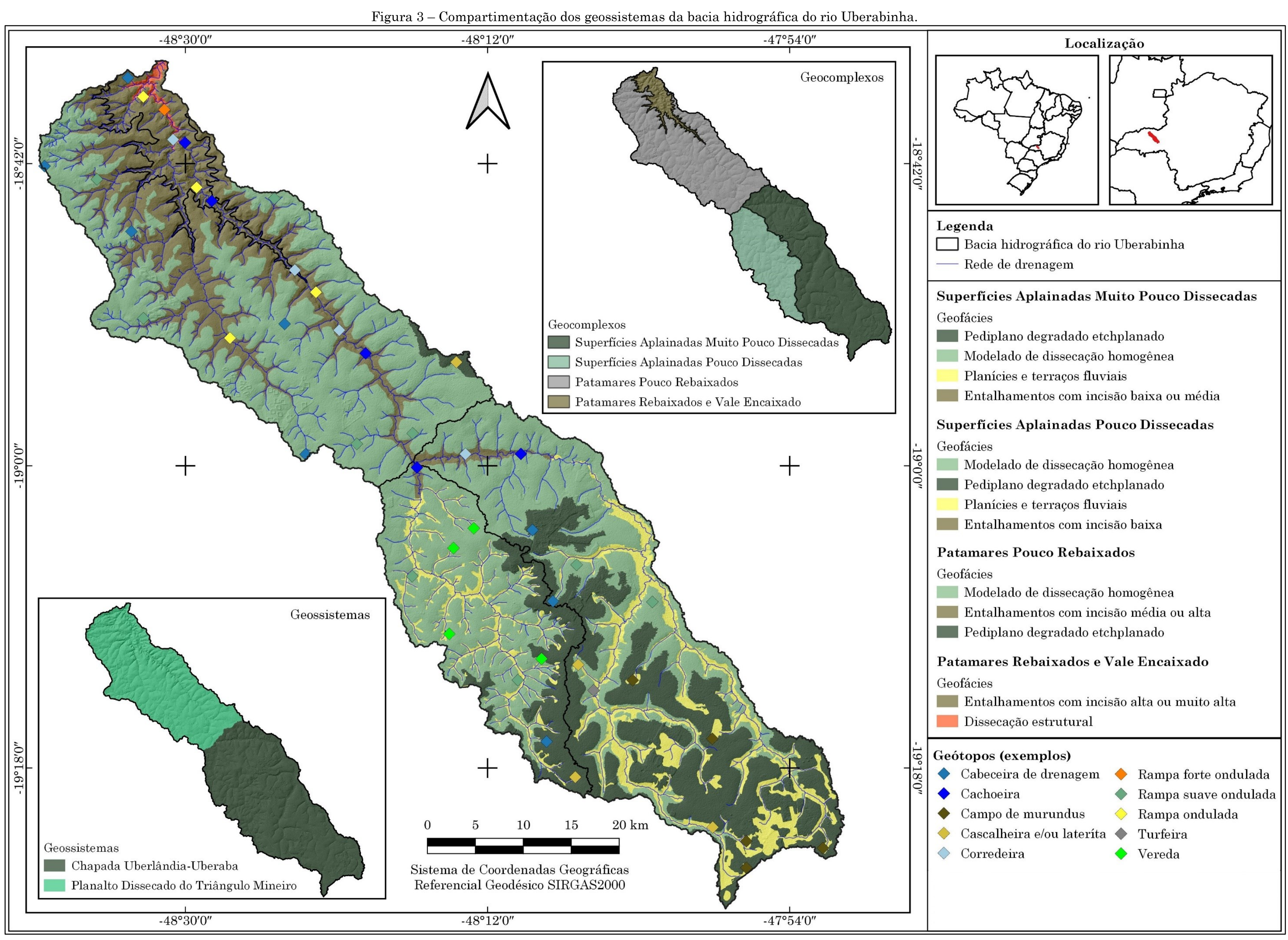

Elaborado pelos autores (2021) 
Tabela 2 - Áreas e percentuais de ocupação da cobertura e uso da terra da bacia hidrográfica do rio Uberabinha.

\begin{tabular}{|c|c|c|c|c|c|c|c|c|c|c|c|c|}
\hline \multirow{3}{*}{ Classes } & \multicolumn{12}{|c|}{ Períodos, áreas e percentuais de ocupação } \\
\hline & \multicolumn{2}{|c|}{1985} & \multicolumn{2}{|c|}{1992} & \multicolumn{2}{|c|}{1999} & \multicolumn{2}{|c|}{2006} & \multicolumn{2}{|c|}{2013} & \multicolumn{2}{|c|}{2020} \\
\hline & $\mathrm{km}^{2}$ & $\%$ & $\mathrm{~km}^{2}$ & $\%$ & $\mathrm{~km}^{2}$ & $\%$ & $\mathrm{~km}^{2}$ & $\%$ & $\mathrm{~km}^{2}$ & $\%$ & $\mathrm{~km}^{2}$ & $\%$ \\
\hline Formação florestal & 251,68 & 11,50 & 178,23 & 8,14 & 132,58 & 6,06 & 128,54 & 5,87 & 115,3 & 5,27 & 116,61 & 5,33 \\
\hline Formação savânica & 176,61 & 8,07 & 160,63 & 7,34 & 119,65 & 5,46 & 117,86 & 5,38 & 117,23 & 5,35 & 103,26 & 4,72 \\
\hline Campo alagado & 91,29 & 4,17 & 79,77 & 3,64 & 74,98 & 3,42 & 72,46 & 3,31 & 70,64 & 3,23 & 70,25 & 3,21 \\
\hline Formação campestre & 161,11 & 7,36 & 128,79 & 5,88 & 103,55 & 4,73 & 104,40 & 4,77 & 117,21 & 5,35 & 121,21 & 5,54 \\
\hline Pastagem & 867,32 & 39,61 & 827,42 & 37,79 & 774,62 & 35,38 & 623,97 & 28,50 & 460,67 & 21,04 & 386,16 & 17,64 \\
\hline Soja & 9,88 & 0,45 & 62,13 & 2,84 & 92,95 & 4,25 & 379,16 & 17,32 & 335,05 & 15,30 & 546,61 & 24,97 \\
\hline Café & 14,02 & 0,64 & 0,67 & 0,03 & 2,68 & 0,12 & 1,79 & 0,08 & 0,79 & 0,04 & 2,71 & 0,12 \\
\hline Cana-de-açúcar & 0,02 & 0,00 & 0,02 & 0,00 & 0,02 & 0,00 & 0,06 & 0,00 & 59,95 & 2,74 & 114,27 & 5,22 \\
\hline $\begin{array}{c}\text { Mosaico de agricultura e } \\
\text { pastagem }\end{array}$ & 309,81 & 14,15 & 314,09 & 14,35 & 216,29 & 9,88 & 227,94 & 10,41 & 310,42 & 14,18 & 332,56 & 15,19 \\
\hline Silvicultura & 108,74 & 4,97 & 133,03 & 6,08 & 111,84 & 5,11 & 106,88 & 4,88 & 101,71 & 4,65 & 97,28 & 4,44 \\
\hline Área urbanizada & 60,64 & 2,77 & 83,24 & 3,80 & 97,92 & 4,47 & 109,3 & 4,99 & 122,93 & 5,61 & 133,76 & 6,11 \\
\hline $\begin{array}{l}\text { Outras áreas não } \\
\text { vegetadas }\end{array}$ & 19,48 & 0,89 & 5,28 & 0,24 & 4,59 & 0,21 & 4,09 & 0,19 & 6,44 & 0,29 & 8,32 & 0,38 \\
\hline Corpos d'água & 4,31 & 0,20 & 6,13 & 0,28 & 5,71 & 0,26 & 5,27 & 0,24 & 5,35 & 0,24 & 5,31 & 0,24 \\
\hline $\begin{array}{l}\text { Outras lavouras } \\
\text { temporárias }\end{array}$ & 114,51 & 5,23 & 209,99 & 9,59 & 452,04 & 20,65 & 307,7 & 14,05 & 365,73 & 16,70 & 151,11 & 6,90 \\
\hline Total & $2.189,42$ & 100,00 & $2.189,42$ & 100,00 & $2.189,42$ & 100,00 & $2.189,42$ & 100,00 & $2.189,42$ & 100,00 & $2.189,42$ & 100,00 \\
\hline
\end{tabular}

Fonte: Adaptado de MapBiomas (2021). 
O decréscimo gradual da cobertura vegetal nativa tem sido ocasionado de diferentes formas de apropriação do território da bacia. $\mathrm{Na}$ Chapada Uberlândia-Uberaba a agricultura tecnificada avança sobre áreas úmidas. No Planalto Dissecado do Triângulo Mineiro, porção em que o relevo possui maior ondulação contribuiu para um menor incentivo a agricultura mecanizada. As áreas de agricultura no Planalto são mais restritas que na Chapada.

Dessa forma, há dois grandes grupos sociais que interferem no uso da terra da bacia: os agricultores capitalizados na Chapada Uberlândia-Uberaba, vinculados ao agronegócio; e os pequenos agricultores e pecuaristas no Planalto Dissecado do Triângulo Mineiro. Os dois grupos podem ser identificados pelas classes de uso da terra em forma de mapas (Figura 4).

Outras formas de ocupação, como as mineradoras de argila refratária na Chapada e as Pequenas Centrais Hidrelétricas (PCHs) no Planalto localizam-se de maneira pontual na bacia. 
Figura 4 - Evolução da cobertura e uso da terra da bacia hidrográfica do rio Uberabinha entre os anos 1985 e 2020. A) 1985; B) 1992; C) 1999; D) 2006 ; E) 2013 ; F) 2020.

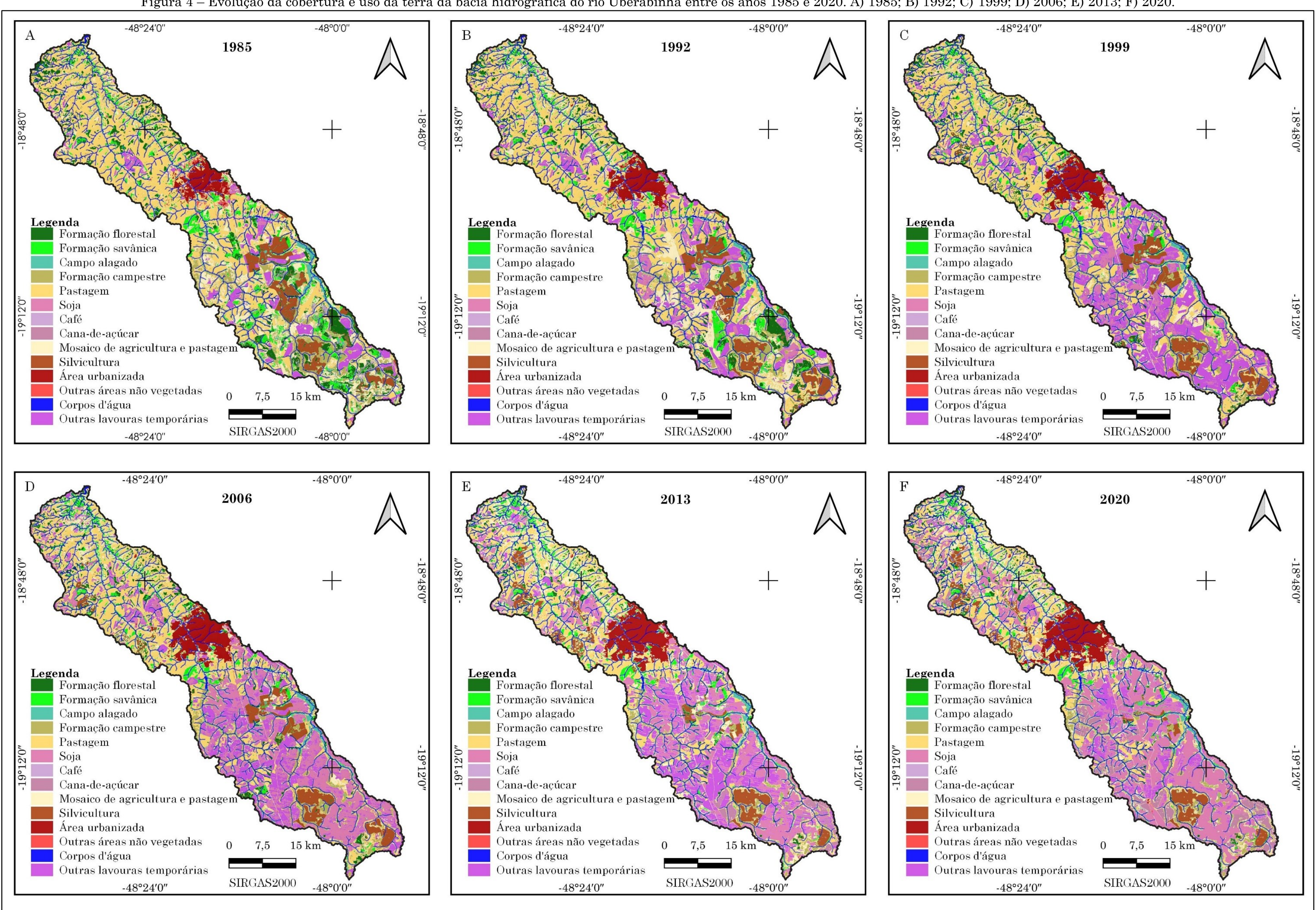

Elaborado pelos autores (2021) 


\section{Vulnerabilidade à perda de solos}

A vulnerabilidade à perda de solos foi obtida a partir da atribuição de valores de vulnerabilidade $(1,0 \quad$ a 3,0$)$ às variáveis fisiográficas pertencentes à geologia, geofácies, solos, intensidade pluviométrica e cobertura e uso da terra (Quadro 3). Os valores foram baseados nas indicações de Crepani et al. (2001) a partir da tendência que cada variável possui em relação à estabilidade/vulnerabilidade à perda de solos.

Quadro 3-Valores de vulnerabilidade das variáveis fisiográficas.

\begin{tabular}{|c|c|c|}
\hline $\begin{array}{l}\text { Componentes } \\
\text { fisiográficos }\end{array}$ & $\begin{array}{c}\text { Variáveis } \\
\text { Fisiográficas } \\
\end{array}$ & $\begin{array}{c}\text { Valores de } \\
\text { vulnerabilidade }\end{array}$ \\
\hline \multirow{4}{*}{ Geologia } & Coberturas detrítico-lateríticas (lateritas) & 1,4 \\
\hline & Formação Marília (arenitos) & 2,4 \\
\hline & Formação Serra Geral (basaltos) & 1,5 \\
\hline & Grupo Araxá (micaxistos) & 2,0 \\
\hline \multirow{8}{*}{ Geofácies } & Pediplano degradado etchplanado & 1,0 \\
\hline & Modelado de dissecação homogênea & 2,0 \\
\hline & Planícies e terraços fluviais & 3,0 \\
\hline & Entalhamento com incisão baixa & 1,5 \\
\hline & Entalhamento com incisão baixa ou média & 2,0 \\
\hline & Entalhamento com incisão média ou alta & 2,5 \\
\hline & Entalhamento com incisão alta ou muito alta & 3,0 \\
\hline & Dissecação estrutural & 3,0 \\
\hline \multirow{3}{*}{ Solos } & Cambissolos/Neossolos & 2,5 \\
\hline & Gleissolos/Organossolos & 3,0 \\
\hline & Latossolos/Argissolos & 1,0 \\
\hline \multirow{2}{*}{$\begin{array}{l}\text { Intensidade } \\
\text { pluviométrica }\end{array}$} & $175,00 \mathrm{~mm}-214,28 \mathrm{~mm}(1.400 \mathrm{~mm}-1.500 \mathrm{~mm})$ & 1,7 \\
\hline & $187,50 \mathrm{~mm}-228,57 \mathrm{~mm}(1.500 \mathrm{~mm}-1.600 \mathrm{~mm})$ & 1,8 \\
\hline \multirow{13}{*}{$\begin{array}{l}\text { Cobertura e } \\
\text { uso da terra }\end{array}$} & Formação florestal & 1,4 \\
\hline & Formação savânica & 1,7 \\
\hline & Campo alagado & 3,0 \\
\hline & Formação campestre & 1,9 \\
\hline & Pastagem & 2,8 \\
\hline & Soja & 2,7 \\
\hline & Café & 2,5 \\
\hline & Cana-de-açúcar & 2,5 \\
\hline & Mosaico de agricultura e pastagem & 2,6 \\
\hline & Silvicultura & 2,1 \\
\hline & Área urbanizada & - \\
\hline & $\begin{array}{l}\text { Outras áreas não vegetadas e outras lavouras } \\
\text { temporárias }\end{array}$ & 2,7 \\
\hline & Corpos d'água & - \\
\hline
\end{tabular}

Fonte: Adaptado de Crepani et al. (2001).

A geologia apresenta, em grande parte, áreas moderadamente estáveis, enquanto que as geofácies variam conforme o ambiente. Os valores de vulnerabilidade das geofácies foram atribuídos conforme as duas classes de declividade predominantes. As exceções são as planícies e terraços fluviais por apresentarem terrenos ambientalmente frágeis (Quadro 4). Em relação aos solos, a área de estudo possui a predominância de solos desenvolvidos, por isso foram atribuídos os valores de estabilidade na maioria das classes. 
Quadro 4-Classes de declividade predominantes por geofácies.

\begin{tabular}{|l|c|c|}
\hline \multicolumn{1}{|c|}{ Geofácies } & $\begin{array}{c}\text { Classes de declividade } \\
\text { predominantes }\end{array}$ & $\begin{array}{c}\text { Valores de } \\
\text { vulnerabilidade }\end{array}$ \\
\hline Pediplano degradado etchplanado & $0 \%-3 \%$ e $3 \%-8 \%$ & 1,0 \\
\hline Modelado de dissecação homogênea & $3 \%-8 \%$ e $8 \%-20 \%$ & 2,0 \\
\hline Planícies e terraços fluviais & $3 \%-8 \%$ e $0 \%-3 \%$ & 3,0 \\
\hline Entalhamento com incisão baixa & $3 \%-8 \%$ e $8 \%-20 \%$ & 1,5 \\
\hline $\begin{array}{l}\text { Entalhamento com incisão baixa ou } \\
\text { média }\end{array}$ & $8 \%-20 \%$ e $3 \%-8 \%$ & 2,0 \\
\hline $\begin{array}{l}\text { Entalhamento com incisão média ou } \\
\text { alta }\end{array}$ & $8 \%-20 \%$ e $20 \%-45 \%$ & 2,5 \\
\hline $\begin{array}{l}\text { Entalhamento com incisão alta ou } \\
\text { muito alta }\end{array}$ & $20 \%-45 \%$ e > $>45 \%$ & 3,0 \\
\hline Dissecação estrutural & $20 \%-45 \%$ e $>45 \%$ & 3,0 \\
\hline
\end{tabular}

Fonte: Adaptado de Crepani et al. (2001).

A pluviosidade foi apresentada a partir das definições de intensidade pluviométrica de Crepani et al. (2001), definida em classes, mínima e máxima (ambas em $\mathrm{mm} / \mathrm{mês}$ ). A bacia do rio Uberabinha possui de sete a oito meses de período chuvoso. Dessa forma, para obtenção da intensidade pluviométrica máxima foi divido o maior valor de precipitação média anual dentro de uma classe (intervalo) por sete e, de modo oposto, para a obtenção da mínima dividiu-se por oito o menor valor de precipitação média anual da mesma classe (Figura 5). 
Figura 5 - Unidades de vulnerabilidade da bacia hidrográfica do rio Uberabinha. A) Geologia; B) Geofácies; C) Solos; D) Pluviosidade; E) Cobertura e uso da terra.

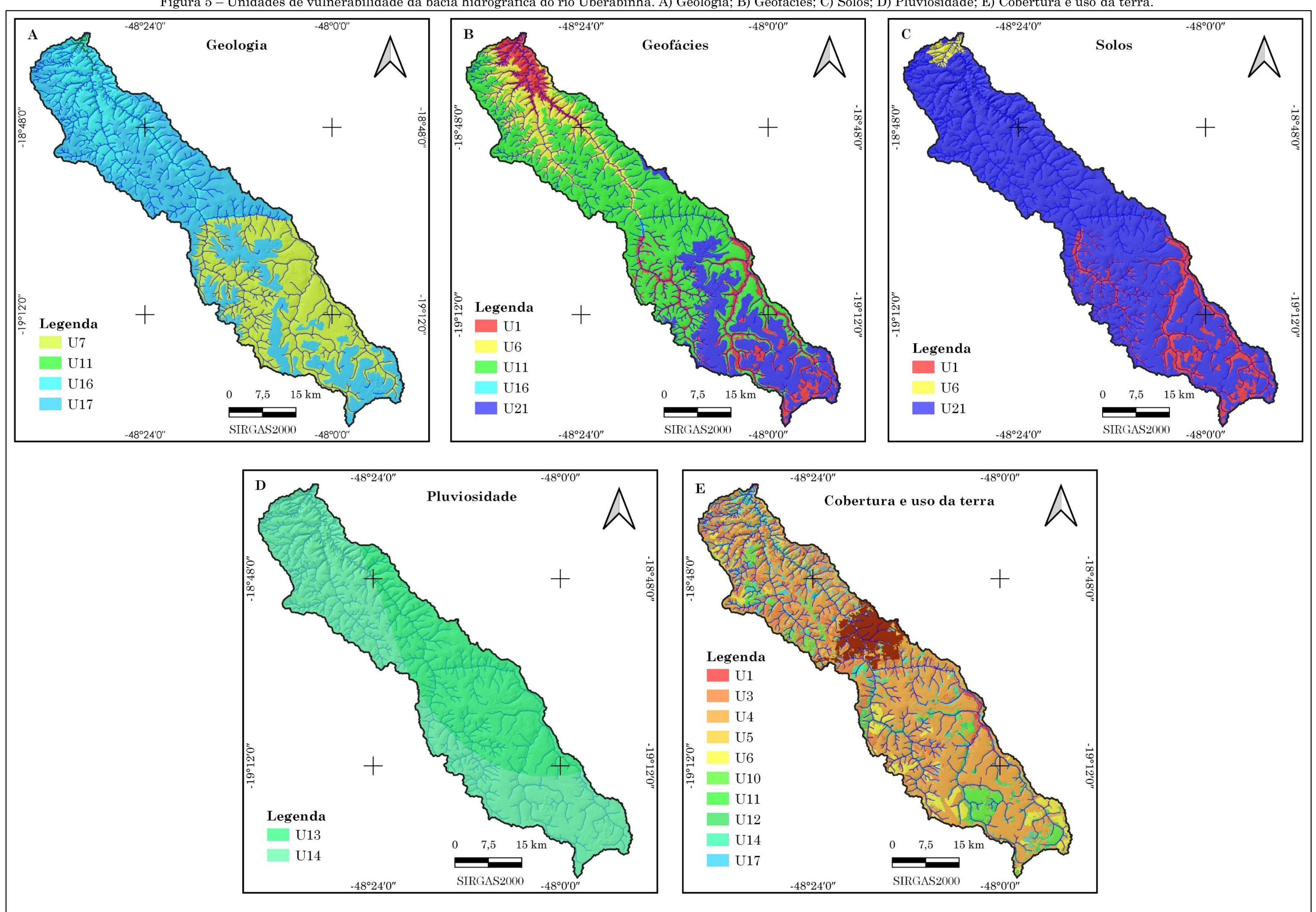

Elaborado pelos autores (2021). 
A partir da definição dos valores de vulnerabilidade nos componentes fisiográficos realizou-se a sobreposição dos mapas temáticos e a extração da média aritmética para obtenção das unidades de paisagem. Em seguida foram agregados os valores nas classes de vulnerabilidade à perda de solos de Crepani et al. (2001) e calculados as áreas e os percentuais de ocupação em cada geocomplexo da bacia do rio Uberabinha (Tabela 3).

Tabela 3 - Áreas e percentuais de vulnerabilidade por geocomplexo.

\begin{tabular}{lccc}
\hline \multicolumn{1}{c}{ Geocomplexos } & Graus de vulnerabilidade & $\mathbf{k m}^{\mathbf{2}}$ & $\mathbf{\%}$ \\
\hline & Moderadamente vulnerável & 169,11 & 20,17 \\
Superfícies Aplainadas & Medianamente estável/vulnerável & 238,11 & 28,40 \\
Muito Pouco & Moderadamente estável & 416,39 & 49,66 \\
Dissecadas & Estável & 6,64 & 0.79 \\
& Área impermeabilizada & 8,25 & 0,98 \\
& Total & 838,50 & 100,00 \\
\hline & Moderadamente vulnerável & 69,35 & 17,44 \\
Superfícies Aplainadas & Medianamente estável/vulnerável & 143,02 & 35,96 \\
Pouco Dissecadas & Moderadamente estável & 184,39 & 46,37 \\
& Estável & 0,93 & 0,23 \\
& Área impermeabilizada & 0,00 & 0,00 \\
& Total & 397,69 & 100,00 \\
\hline & Moderadamente vulnerável & 0,00 & 0,00 \\
Patamares & Medianamente estável/vulnerável & 225,24 & 26,62 \\
Rebaixados & Moderadamente estável & 495,49 & 58,56 \\
& Estável & 0,00 & 0,00 \\
& Área impermeabilizada & 125,43 & 14,82 \\
& Total & 846,16 & 100,00 \\
\hline Patamares Rebaixados & Moderadamente vulnerável & 2,64 & 2,47 \\
e Vale Encaixado & Moderadamente estável & 81,04 & 75,69 \\
& Estável & 23,39 & 21,85 \\
& Área impermeabilizada & 0,00 & 0,00 \\
& Total & 0,00 & 0,00 \\
& Medianamente estável/vulnerável & 107,07 & 100,00 \\
\hline
\end{tabular}

Fonte: Adaptado de Crepani et al. (2001).

Os resultados indicam que as áreas moderadamente estáveis se destacam em todos os geocomplexos. Com exceção dos Patamares Rebaixados e Vale Encaixado, cuja referida classe é a segunda em área de ocupação, os demais geocomplexos apresentam os terrenos moderadamente estáveis como terrenos predominantes. Essa condição indica que as variáveis possuem tendências à uma relativa estabilidade em sua maioria.

Como exemplo, a presença de lateritas em pediplanos e modelados de dissecação homogênea, além de Latossolos nos geocomplexos Superfícies Aplainadas Muito e Pouco Dissecadas, contribuíram para que as áreas moderadamente estáveis sejam significativas. Os basaltos em modelados de dissecação homogênea e os Latossolos nos Patamares Rebaixados também definiram a predominância de áreas definidas como moderadamente estáveis.

A classe medianamente estável/vulnerável também é representativa nos geocomplexos. Esse resultado decorreu da média de algumas variáveis que tendem à estabilidade (solos) e outras à vulnerabilidade (uso da terra). Os terrenos moderadamente vulneráveis estão nas porções de solos hidromórficos na Chapada Uberlândia-Uberaba em áreas dos Patamares Rebaixados e Vale Encaixado. As áreas estáveis são bastante restritas, associadas em uma combinação que inclui os pediplanos (Figura 6). 


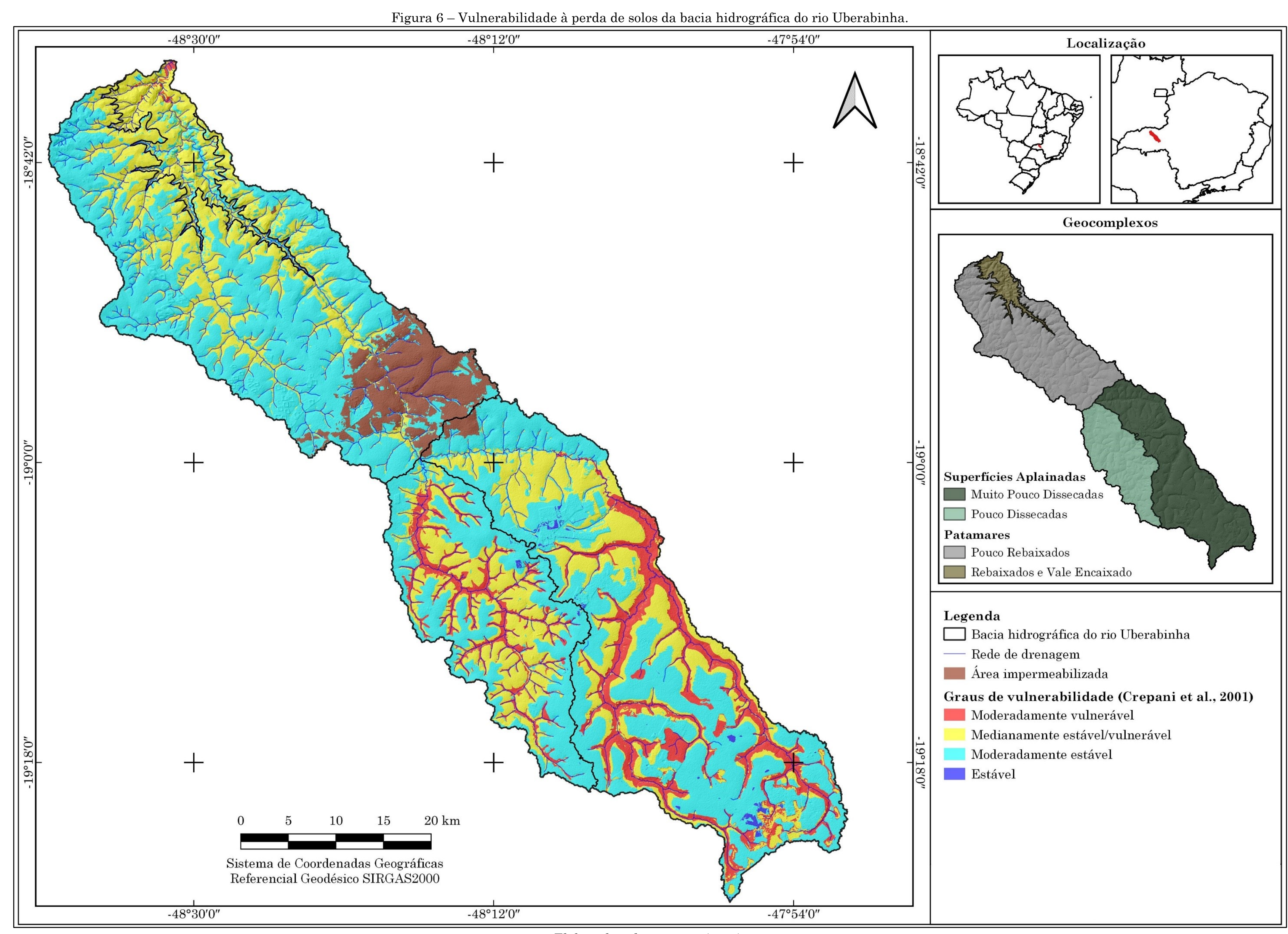

Elaborado pelos autores (2021) 


\section{Perfis geoecológicos}

Os perfis geoecológicos constituem em um esquema representativo de análise integrada da paisagem. Nesse sentido, foram estabelecidos quatro transectos, um em cada geocomplexo, para se obter uma síntese da realidade terrestre numa perspectiva vertical (geohorizontes) (Figuras 7).

Figura 7 - Localização dos transectos nos geocomplexos.

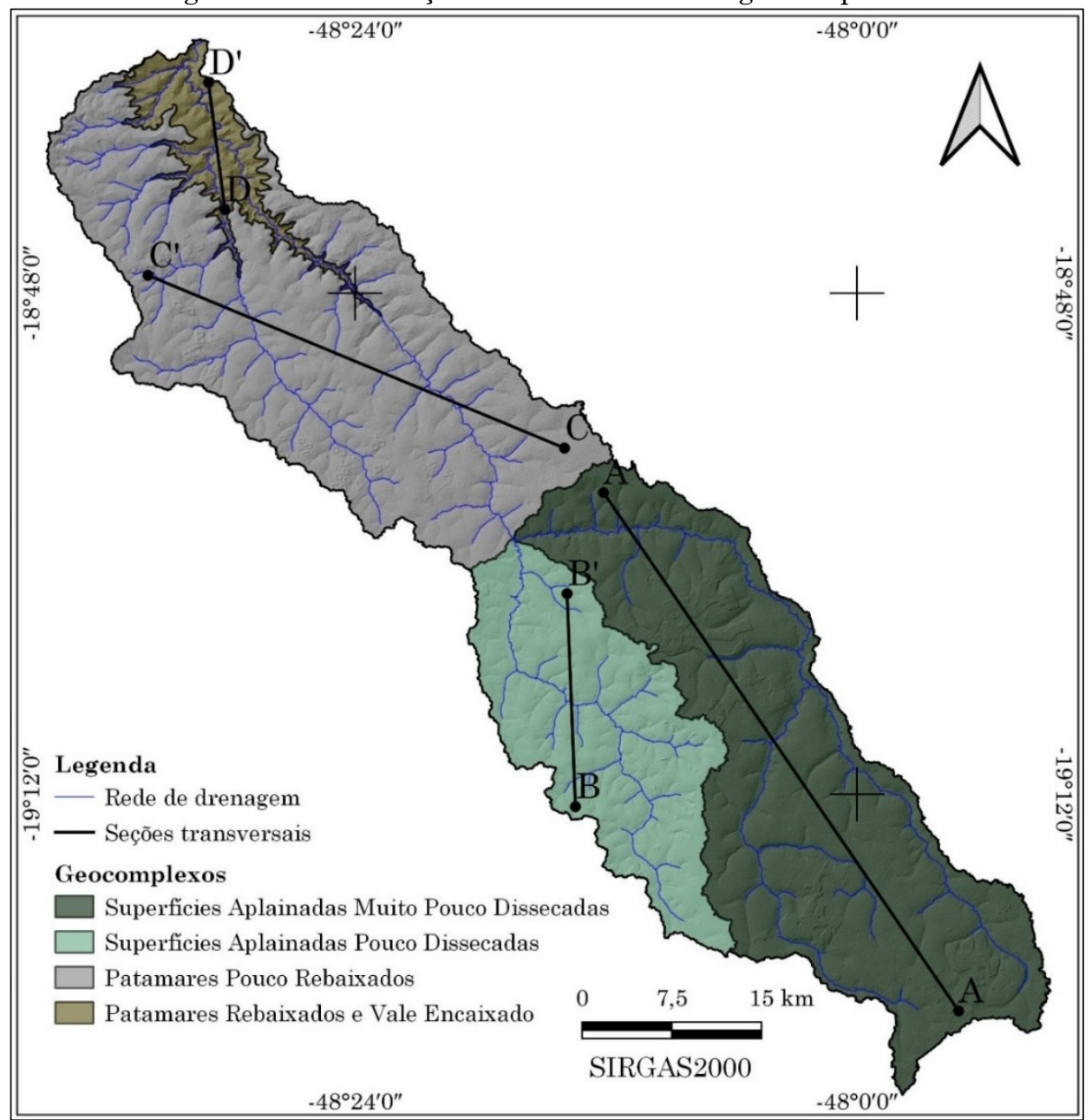

Elaborado pelos autores (2021).

Os perfis A - A' e B - B', de extensão pouco acima de $54 \mathrm{~km}$ e $18 \mathrm{~km}$ respectivamente, apresentam características semelhantes. $\mathrm{Na}$ geologia, tanto os arenitos quanto as coberturas lateríticas são amplamente representadas. Apenas no perfil A - A', no trecho que perpassa o rio Uberabinha, atinge-se os basaltos são aflorantes. Nos amplos divisores, sobretudo em A - A', os pediplanos são predominantes, ao passo que suaves vertentes representam o modelado, melhor representado no perfil B - B'.

Ainda nos perfis A - A' e B - B', os solos de maior representatividade correspondem aos Latossolos. Somente nas planícies e terraços fluviais são encontrados Gleissolos e Organossolos. Nesse contexto, os dois perfis situados na Chapada Uberlândia-Uberaba corroboram os aspectos naturais descritos anteriormente: em geral o relevo é aplainado ou suave-ondulado, o que favorece os processos pedogenéticos em detrimento dos morfogenéticos. Dessa forma, a agricultura mecanizada é principal ocupação.

$\mathrm{O}$ perfil $\mathrm{C}-\mathrm{C}$, de pouco mais de $38 \mathrm{~km}$, transcorre os basaltos na calha dos cursos d'água (entalhamentos), bem como nas médias e baixas vertentes (modelado de dissecação homogênea). As coberturas detrítico-lateríticas encontram-se nas áreas mais elevadas. Embora o relevo seja mais ondulado que na chapada, os Latossolos ainda são a classe principal nesse geocomplexo. O uso da terra que é o componente de maior variação no perfil, sendo as de maior expressão a área urbanizada, agricultura e pastagem. 
Por fim, o perfil D - D', de extensão pouco superior a $11 \mathrm{~km}$, demonstra uma diferença em relação aos demais geocomplexos. Os basaltos são encontrados na maior parte das vertentes, em entalhamentos mais incisivos. Os micaxistos afloram na calha do rio Uberabinha e trechos finais de outras drenagens, em dissecação estrutural. As classes de solos dependem do relevo, sendo Latossolos, Cambissolos e Neossolos, assim como o uso terra, que varia de pastagens a cobertura vegetal, conforme a declividade.

Sobre a vulnerabilidade à perda de solos, observa-se que nos transectos da chapada (A A' e B - B') as áreas moderadamente estáveis ocorrem principalmente nos amplos divisores topográficos. Contudo, as áreas úmidas são consideravelmente vulneráveis, sendo apontados nos vales fluviais e suas adjacências.

Nos transectos do planalto ocorre uma maior diferença nas classes de vulnerabilidade. Enquanto no perfil C - C' há uma intercalação entre áreas moderadamente e medianamente estáveis/vulneráveis, no perfil D - D' as áreas medianamente estáveis/vulneráveis são predominantes (Figura 8).

\section{CONSIDERAÇÕES FINAIS}

A boa qualidade ambiental, que inclui uma série de aspectos intimamente ligados à qualidade de vida, requer uma associação equilibrada de ações subordinadas às fragilidades e potencialidades do meio ambiente. Nesse contexto, busca-se minimizar os impactos das ações econômicas sobre a natureza por meio de procedimentos que visam identificar as características naturais e as formas de uso dos recursos disponíveis nos territórios. O diagnóstico integrado dos componentes fisiográficos e dos usos da terra, por meio da compartimentação paisagística, fornece informações importantes aos instrumentos de planejamento e gestão ambiental.

As bacias hidrográficas têm sido adotadas para o entendimento e aplicação de tais premissas. É fundamental reconhecer que as bacias são internamente heterogêneas, pois se configuram como um conjunto de paisagens diferenciadas espacialmente. Nessa perspectiva, o artigo apresentou uma compartimentação da paisagem da bacia do rio Uberabinha baseada na concepção geossistêmica da escola francesa. A referida bacia apresenta especificidades internas que justificam a compartimentação da paisagem de forma multiescalar. Os mapeamentos dos componentes fisiográficos, da cobertura e uso da terra e da vulnerabilidade à perda de solos demonstraram essa perspectiva.

Diante do exposto, espera-se que esta análise da bacia do rio Uberabinha possa contribuir para a proposição de diretrizes de planejamento e gestão ambiental, visto que sua exploração tem se mostrado ecologicamente predatória, condição não muito diferente da maioria das bacias hidrográficas brasileiras. 


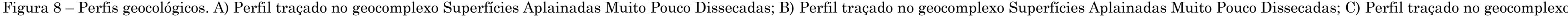
Patamares Pouco Rebaixados; D) Perfil traçado no geocomplexo Patamares Rebaixados e Vale Encaixado.

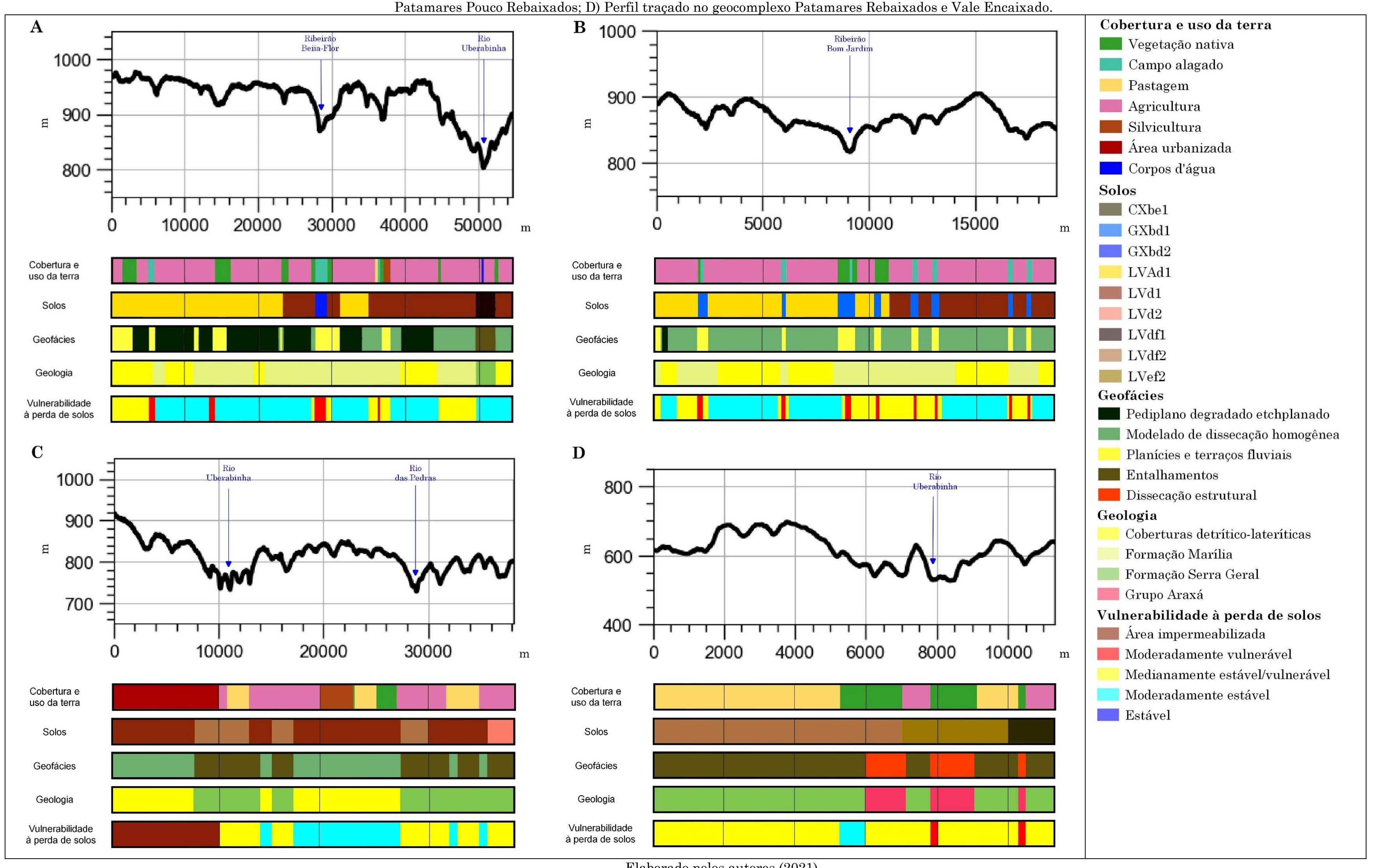




\section{AGRADECIMENTOS}

O primeiro autor agradece à Coordenação de Aperfeiçoamento de Pessoal de Nível Superior (CAPES) pela concessão da bolsa de doutorado.

\section{REFERÊNCIAS}

AB'SÁBER, A. N. Os domínios de natureza no Brasil: potencialidades paisagísticas. 7. ed. São Paulo: Ateliê Editorial, 2012. 158 p.

ALOS PALSAR. Imagens Alos Palsar 2011, resolução espacial $12,5 \mathrm{~m}$. Disponível em: https://search.asf.alaska.edu/\#/. Acesso em: Oct. $20^{\text {th }} 2020$.

ARIAS-GARCÍA, J.; GÓMEZ-ZOTANO, J.; DELGADO-PEÑA, J. J. Classifying landscape in endorheic basins: a methodological approach for the implementation of the European landscape convention. European Journal of Geography, v. 8, n. 2, p. 55-77, fev. 2017.

AGÊNCIA NACIONAL DE ÁGUAS. Sistema de Informações Hidrológicas. Disponível em: http://www.snirh.gov.br/hidroweb/serieshistoricas. Acesso em: Sep. 20 2021.

BERTRAND, G. Paisagem e geografia física global: esboço metodológico. Cadernos de Ciências da Terra, n.13, 1971. (Trad. Paysage et géographie physique globale: esquisse méthodologique, 1968).

BERTRAND, G.; BERTRAND, C. Uma geografia transversal e de travessias: o meio ambiente através dos territórios e das temporalidades. (Translation: Messias Modesto dos Passos). Maringá: Ed. Massoni, 2009. 332 p.

BRASIL. Mapeamento do uso e cobertura da terra do Cerrado: Projeto TerraClass Cerrado 2013. Brasília: MMA, 2015. 67 p. Disponível em: http://www.dpi.inpe.br/tccerrado. Acesso em: Feb. $15^{\text {th }} 2019$

CARLIER, J.; DOYLE, M.; FINN, J. A.; Ó HUALLACHÁIN; MORAN, J. A landscape classification map of Ireland and its potential use in national land use monitoring. Journal of Environmental Management, v. 289, p. 1 - 12, 2021.

https://doi.org/10.1016/j.jenvman.2021.112498

CAVALCANTI, L. C. S. Cartografia de paisagens: fundamentos. São Paulo: Oficina de Textos, 2014. 95 p.

CAVALCANTI, L. C. S. Da descrição de áreas à teoria dos geossistemas: uma abordagem epistemológica sobre sínteses naturalistas. $216 \mathrm{f}$. Tese (Doutorado) - Federal University of Pernambuco, Recife, 2013.

CREPANI, E. et al. Sensoriamento remoto e geoprocessamento aplicados ao Zoneamento Ecológico-Econômico e ao ordenamento territorial. São José dos Campos: INPE, 2001. 124 p.

EMPRESA DE PESQUISA AGROPECUÁRIA DE MINAS GERAIS. Mapa de reconhecimento dos solos no Triângulo Mineiro. Serviço Nacional de Levantamento e Conservação dos Solos. 1980. Disponível

em:

http://library.wur.nl/WebQuery/isric/21562. Acesso em: May $5^{\text {th }}$ de 2016 .

FARIA, K. M. S.; SILVA, E. V. Dinâmica das paisagens antropogênicas na microrregião do Vão do Paraná (GO). Revista Geográfica Acadêmica, v. 14, n. 2, p. 141-152, 2020.

FELTRAN FILHO, A.; LIMA, E. F. DE. Considerações morfométricas da bacia do rio Uberabinha - Minas Gerais / Morphometric considerations of the Uberabinha river basin Minas Gerais. Sociedade \& Natureza, v. 19, n. 1, 1 nov. 2007.

GÜLÇIN, D.; YILMAZ, K. T. Mapping landscape potential for supporting green infrastructure: the case of a watershed in Turkey. Land, v. 9, p. $1-13$, 2020. https://doi.org/10.3390/land9080268

INSTITUTO BRASILEIRO DE GEOGRAFIA E ESTATÍSTICA. Arquivo vetorial do território brasileiro. Disponível em: https://mapas.ibge.gov.br/bases-e-

referenciais/bases-cartograficas/malhas-digitais.

Acesso em: Dec. 20th 2020.

INSTITUTO BRASILEIRO DE GEOGRAFIA E ESTATÍSTICA. Divisão regional do Brasil em Regiões Geográficas Imediatas e Regiões Geográficas Intermediárias. Rio de Janeiro: IBGE, 2017. Disponível em: https://www.ibge.gov.br/apps/regioes_geograficas/.

Acesso em: May $6^{\text {th }} 2020$.

INSTITUTO BRASILEIRO DE GEOGRAFIA E ESTATÍSTICA. Mapa de clima do Brasil escala 1:5.000.000. Rio de Janeiro: IBGE, 2002. Disponível em:

https://geoftp.ibge.gov.br/informacoes_ambientais/c limatologia/mapas/brasil/Map_BR_clima_2002.pdf. Acesso em: Feb. $1^{\text {st }} 2020$.

INSTITUTO BRASILEIRO DE GEOGRAFIA E ESTATÍSTICA. Uberlândia: população estimada. Disponível

em: https://cidades.ibge.gov.br/brasil/mg/uberlandia/pa norama. Acesso em: Sep. $20^{\text {th }} 2021$.

INSTITUTO MINEIRO DE GESTÃO DAS ÁGUAS. Rede de drenagem de Minas Gerais em formato shapefile. Belo Horizonte: Igam, 2012. Disponível

em: http://idesisema.meioambiente.mg.gov.br/. Acesso em: Sep. $19^{\text {th }} 2019$.

KING, L, C. A. Geomorfologia do Brasil Oriental. Revista Brasileira de Geografia, Rio de Janeiro. v. 18 , n. 2 , p. 147-266, 1956.

LIMA, E. M.; CORRÊA, A. C. B. Compartimentação da paisagem em bases geossistêmicas do alto curso do rio Canhoto, Planalto da Borborema, Nordeste do Brasil. GeoUERJ, n. 35, p. 1-19, 2019. https://doi.org/10.12957/geouerj.2019.38012

MAPBIOMAS. Coleção 6 da série anual de mapas de cobertura e uso de solo do Brasil. 2021. Disponível em: http://mapbiomas.org. Acesso em: Sep.15th 2021.

MARENT, B. R.; PORTILHO, S. Unidades de paisagem na bacia hidrográfica do Ribeirão Preto, Serra do Gandarela-MG. Geousp - Espaço e 
Tempo (Online), v. 21, n. 1, p. 138-155, abr. 2017. https://doi.org/10.11606/issn.2179-

0892.geousp.2017.116477

MIRANDA, L. C.; SILVA, E. V.; GORAYEB, A.; RABELO, F. D. B. Zoneamento Geoecológico como Instrumento para o Planejamento e Gestão Ambiental da Ilha do Príncipe. Revista Eletrônica Casa de Makunaima, v. 1, p. 131-144, 2018. https://doi.org/10.24979/makunaima.v1i1.517

MOREIRA, V. B.; PEREZ FILHO, A. Das superfícies de aplainamento aos pulsos climáticos holocênicos: a evolução da paisagem em relevos de chapada. Sociedade \& Natureza, v. 32, p. 176195, 23 mar. 2020. https://doi.org/10.14393/SN-v322020-46867

NICOLAU, R. F. Vulnerabilidade da paisagem à perda de solos da bacia hidrográfica do rio do Peixe - Goiás. Caminhos de Geografia, v. 19, n. 66, p. $285-296$ jun.

2018. https://doi.org/10.14393/RCG196620

OLIVEIRA, C. S.; MARQUES NETO, R. Características estruturais dos geossistemas da bacia hidrográfica do ribeirão Pari/MG. Revista de Geografia, v. 1, p. 1-12, 2015.

OLIVEIRA, T. A.; VIADANA, A. G.; PEREIRA, A. A. Fragilidade ambiental e dinâmica geossistêmica: mapeamento da paisagem na bacia hidrográfica do rio Lourenço Velho, sul do estado de Minas GeraisBrasil. Caminhos De Geografia, v. 20, n. 71, p. 504-516, ago. 2019 https://doi.org/10.14393/RCG207146666

PACHECO; F. E. R. C.; SERRANO; P. M.; CAXITO; F. A.; MOURA; C. D.; QUINTÃO; D. A. Geologia da Folha Uberlândia SE.22-Z-B-VI: escala 1:100.000. Belo Horizonte: CODEMIG/UFMG, 2017, 37 p.

QGIS.org, 2022. QGIS Geographic Information System. QGIS Association. http://www.qgis.org

RODRIGUEZ, J. M. M.; SILVA, E. V.; CAVALCANTI, A. P. B. Geoecologia das paisagens: uma visão geossistêmica da análise ambiental. 2. ed. Fortaleza: Edições UFC, 2007. 222 p.

ROSA, R. M.; FERREIRA, V. O.; BRITO, J. L. S. Mapa de reconhecimento geológico da bacia do rio Uberabinha (MG): procedimento experimental utilizando coeficientes de concordância. Caminhos de Geografia, v. 20, n. 70, 2019, p. 507-518. https://doi.org/10.14393/RCG207042721

ROSA, R. M. Unidades de paisagem e zoneamento: subsídios para o planejamento ambiental na bacia do rio Uberabinha-MG. Thesis (Master's degree), Federal University of
Uberlândia, Graduate Program in Geography, 2017, $118 \mathrm{p}$.

SANTOS, D. J.; RUCHKYS, U. A.; TRAVASSOS, L. E. P. Perfil Geoecológico do Parque Nacional da Serra do Gandarela, Minas Gerais, Brasil. Sociedade \& Natureza, v. 33, p. 1-10, 2 fev. 2021.

https://doi.org/10.14393/SN-v33-2021-57012

SANTOS, H. G. et al. Sistema Brasileiro de Classificação de Solos. Brasília: Embrapa, $5^{\mathrm{a}}$ ed., 2018.

SANTOS, R. F. Planejamento ambiental: teoria e prática. São Paulo: Oficina de Textos, 2004.

SEER, H. J.; MORAES, L. C. Geologia regional do Triângulo Mineiro. Belo Horizonte: CODEMIG/UFMG, 2017, 123 p.

SCHNEIDER, M. O. Bacia do rio Uberabinha: uso agrícola do solo e meio ambiente. Thesis (Doctorate in Physical Geography), Faculty of Philosophy, Letters and Human Sciences, University of São Paulo, 1996, $157 \mathrm{p}$.

SOTCHAVA, V. B. O estudo de geossistemas. Métodos em questão, IG-USP, São Paulo, n. 16, 1977, $51 \mathrm{p}$.

STRAHLER, A. N. Hypsometric (area-altitude): analysis of erosional topography. Geol. Soc. America Bulletin, 63(10), 1952, p. 1117-1142. https://doi.org/10.1130/0016

7606(1952)63[1117:HAAOET]2.0.CO;2

TRICART, J. Ecodinâmica. Rio de Janeiro: IBGE, SUPREN, 1977. 97 p.

TROMBETA, L. R; LEAL, A. C. Planejamento ambiental e geoecologia das paisagens: contribuições para a bacia hidrográfica do córrego Guaiçarinha, município de Álvares Machado, São Paulo, Brasil. Revista Formação (online), v. 3; n.23, p. 187-216, 2016.

\section{CONTRIBUIÇÃO DOS AUTORES}

Rafael Mendes Rosa concebeu o estudo, determinou a metodologia, confeccionou os mapas e os perfis geoecológicos e redigiu os resultados. Vanderlei de Oliveira Ferreira elaborou o resumo, a introdução, as considerações finais e revisou a metodologia e os resultados, incluindo adaptações à versão preliminar do estudo. 